\title{
Hydro-stochastic interpolation coupling with the Budyko approach for prediction of mean annual runoff
}

\author{
Ning Qiu ${ }^{1,2}$, Xi Chen ${ }^{4,1,2}$, Qi Hu ${ }^{3}$, Jintao Liu ${ }^{1,2}$, Richao Huang ${ }^{1,2}$, and Man Gao ${ }^{4,1,2}$ \\ ${ }^{1}$ State Key Laboratory of Hydrology-Water Resources and Hydraulic Engineering, Hohai University, Nanjing, \\ Jiangsu 210098, China \\ ${ }^{2}$ College of Hydrology and Water Resources, Hohai University, Nanjing, Jiangsu 210098, China \\ ${ }^{3}$ School of Natural Resources, University of Nebraska-Lincoln, Lincoln, NE 68583, USA \\ ${ }^{4}$ Institute of Surface-Earth System Science, Tianjin University, Tianjin 300072, China
}

Correspondence: Xi Chen (xichen@hhu.edu.cn)

Received: 31 July 2017 - Discussion started: 11 September 2017

Revised: 18 April 2018 - Accepted: 24 April 2018 - Published: 16 May 2018

\begin{abstract}
The hydro-stochastic interpolation method based on traditional block Kriging has often been used to predict mean annual runoff in river basins. A caveat in such a method is that the statistic technique provides little physical insight into relationships between the runoff and its external forcing, such as the climate and land cover. In this study, the spatial runoff is decomposed into a deterministic trend and deviations from it caused by stochastic fluctuations. The former is described by the Budyko method (Fu's equation) and the latter by stochastic interpolation. This coupled method is applied to spatially interpolate runoff in the Huaihe River basin of China. Results show that the coupled method significantly improves the prediction accuracy of the mean annual runoff. The error of the predicted runoff by the coupled method is much smaller than that from the Budyko method and the hydro-stochastic interpolation method alone. The determination coefficient for cross-validation, $R_{\mathrm{cv}}^{2}$, from the coupled method is 0.87 , larger than 0.81 from the Budyko method and 0.71 from the hydro-stochastic interpolation. Further comparisons indicate that the coupled method has also reduced the error in overestimating low runoff and underestimating high runoff suffered by the other two methods. These results confirm that the coupled method offers an effective and more accurate way to predict the mean annual runoff in river basins.
\end{abstract}

\section{Introduction}

The runoff observed at the outlet of a basin is a crucial element for investigating the hydrological cycle of the basin. Because runoff is influenced by both deterministic and stochastic processes, estimating the spatial patterns of runoff and the associated distribution of water resources in ungauged basins has been one of the key problems in hydrology (Sivapalan et al., 2003), and a thorny issue in water management and planning (Imbach, 2010; Greenwood et al., 2011).

In estimating and predicting runoff and regional water resources availability, we have often used regional or global runoff mapping and geostatistical interpolation methods. In these methods, the value of a regional variable at a given location is often estimated as the weighted average of observed values at neighboring locations. This interpolation of runoff, which is assumed as an auto-correlated generalized stochastic field (Jones, 2009), uses secondary information from more than one variable (Li and Heap, 2008). Spatial autocorrelations of the runoff values are measured by the covariance or semi-variance between the runoffs at pairs of locations as a function of their Euclidian distance (such as in ordinary Kriging). The values obtained by the interpolation methods are the best linear unbiased estimate in the sense that the expected bias is zero and the mean squared error is minimized (Skøien et al., 2006). Ordinary Kriging (OK) estimates the local mean as a constant; corresponding residuals are considered random. Because the spatial mean could also be used as a trend or nonstationary variation in space, OK has been 
developed into various geostatistical interpolation methods, such as Kriging with a trend by incorporating a local trend within a confined neighborhood as a smoothly varying function of the coordinates. Block Kriging (BK) is another extension of $\mathrm{OK}$ for estimating a block value instead of a point value by replacing the point-to-point covariance with pointto-block covariance (Wackernagel, 1995).

Unlike precipitation or evaporation, which we often interpolate to find their values at specific locations, runoff is an integrated spatially continuous process in river basins (Lenton and Rodriguez-Iturbe, 1977; Creutin and Obled, 1982; Tabios and Salas, 1985; Dingman et al., 1988; Barancourt et al., 1992; Blöschl, 2005). Streamflows are naturally organized into basins (Dooge, 1986; Sivapalan, 2005); e.g., rivers flow through sub-basins. The river network constrains the water paths from upstream to downstream in a basin. The hierarchically organized river network requires that the sum of the interpolated discharge from sub-basins equals the observed runoff at the outlet of the entire basin. Previous studies have indicated that runoff interpolation may overestimate the actual runoff without adequate information of the spatial variation of the runoff (Arnell, 1995), e.g., neglecting the river network in connecting sub-basins or processing basin runoff at collective points in space (Villeneuve et al., 1979; Hisdal and Tveito, 1993). In nested basins, Gottschalk (1993a, b) developed a hydro-stochastic method to interpolate runoff. It uses the concept that runoff is an integrated process in the hierarchical structure of a river network. The distance between a pair of basins is measured by geostatistical distance instead of the Euclidian distance. The covariogram among points in the conventional spatial interpolation is replaced by the covariogram between basins. In this concept, runoff is assumed spatially homogeneous in basins; i.e., the expected value of the runoff is constant in space (Sauquet, 2006). The observed patterns of runoff reveal systematic deviations from the homogeneity assumption, however, because of the influences from the heterogeneous climate and underlying surface factors.

An alternate method is to describe the hydrological variables of interest in deterministic forms of functions, curves, or distributions, and construct conceptual and mathematical models to predict hydro-climate variability (Wagener et al., 2007). Qiao (1982), Arnell (1992), and Gao et al. (2017) have used such an approach and derived empirical relationships between runoff and its controlling factors of the climate, land cover, and topography in various basins. However, the deterministic method for describing complex runoff patterns suffers from an inevitable loss of information (Wagener et al., 2007) because of the existence of uncertainty in many hydrological processes and especially in observations. Thus, hydrological variables also contain information of a stochastic nature and should be treated as outcomes from deterministic and stochastic processes. A method that combines both deterministic patterns and stochastic variability is Kriging with an external drift (KED) (Goovaerts, 1997; Li and Heap, 2008;
Laaha et al., 2013). It takes the deterministic patterns of spatial variables into account and incorporates them as a local trend of a smoothly varying secondary variable, instead of a function of the spatial coordinates.

The inclusion of deterministic terms in the geostatistical methods has been shown to increase the interpolation accuracy of basin variables, such as mean annual runoff (Sauquet, 2006), stream temperature (Laaha et al., 2013), and groundwater table (Holman et al., 2009). Those deterministic terms are often described by empirical formulae linking spatial features, e.g., variability of the mean annual runoff in elevation (Sauquet, 2006), and the relationship between the mean annual stream temperature and the altitude of gauges (Laaha et al., 2013). As a semi-empirical approach to model the deterministic process of the runoff, the Budyko framework has been popularly used to analyze the relationship between mean annual runoff and the climatic factors, e.g., aridity index (Milly, 1994; Koster and Suarez, 1999; Zhang et al., 2001; Donohue et al., 2007; Li et al., 2013; Greve et al., 2014). Many efforts have been devoted to improving the Budyko method by, for example, including the effects of other external forcing factors, such as land cover (Donohue et al., 2007, 2012; Li et al., 2013; Han et al., 2011; Yang et al., 2007), soil properties (Porporato et al., 2004), topography (Shao et al., 2012; Xu et al., 2013; Gao et al., 2017), hydroclimatic variations of seasonality (Milly, 1994; Gentine et al., 2012; Berghuijs et al., 2014), and groundwater (Istanbulluoglu et al., 2012). However, it has been found that the use of the deterministic equation in the Budyko method alone still comes with large errors in the prediction of runoff in many basins (e.g., Potter and Zhang, 2009; Jiang et al., 2015).

The aim of this study is to combine the stochastic interpolation with the semi-empirical Budyko method to further improve the spatial interpolation/prediction of the mean annual runoff in the Huaihe River basin (HRB), China. In this study, the spatial runoff from sub-basins in the HRB is separated into a deterministic trend and its residuals, which are estimated by the Budyko method and the interpolation method, respectively. The residuals are calculated as the difference between the observed and estimated runoff from the Budyko method, and are used in the stochastic interpolation as described in Gottschalk (1993a, b, 2006). After that, the runoff of any sub-basin is predicted as the sum of the interpolated residuals and the Budyko estimated value. The improved method is tested in the HRB. In addition, the leaveone-out cross-validation approach is applied to evaluate and compare the performances of the three interpolation methods: the Budyko method, hydro-stochastic interpolation, and our coupled Budyko and stochastic interpolation method. 


\section{Methodologies}

\subsection{Spatial estimation of mean annual runoff by the Budyko method}

The Budyko method explains the variability of mean annual water balance on a regional or global scale. It describes the dependence of actual evapotranspiration $(E)$ on precipitation $(P)$ and potential evapotranspiration $\left(E_{0}\right)$ (Williams et al., 2012). Their original relationship $\left(E / P \sim E_{0} / P\right)$ derived by Budyko (1974) is deterministic and nonparametric. It was later developed into parametric forms (Fu, 1981; Choudhury, 1999; Yang et al., 2008; Gerrits et al., 2009; Wang and Tang, 2014). Among them, the one-parameter equation derived by $\mathrm{Fu}$ (1981) and Zhang et al. (2004) has been used frequently. This relationship is written as

$$
\frac{E}{P}=1+\frac{E_{0}}{P}-\left(1+\left(\frac{E_{0}}{P}\right)^{\omega}\right)^{\frac{1}{\omega}}
$$

or

$$
R=P\left(1+\left(\frac{E_{0}}{P}\right)^{\omega}\right)^{\frac{1}{\omega}}-E_{0}
$$

where $P, E, E_{0}$, and $R$ are mean annual precipitation, actual evapotranspiration, potential evapotranspiration, and runoff (units: $\mathrm{mm}$ ), respectively, and $\omega$ is a dimensionless model parameter in the range of $(1, \infty)$. In these formulae, the larger the $\omega$ is, the smaller the partition of precipitation into the runoff.

The parameter $\omega$ in Eq. (1) is determined using observed $P, E_{0}$, and $R$ in gauged sub-basins. The mean value of $\omega$ of a basin can be obtained by averaging $\omega$ of the sub-basins, or by minimizing the mean absolute error (MAE) in fitting the curve in Eq. (1) with $E / P \sim E_{0} / P(E=P-R)$ (Legates and McCabe, 1999). Using the mean value of $\omega$, Eq. (2) can be used to predict ungauged basin runoff or to interpolate the spatial variation of the runoff, using meteorological data in targeted sub-basins (Parajka and Szolgay, 1998).

\subsection{Hydro-stochastic interpolation method}

Gottschalk (1993a) described the hydro-stochastic interpolation method based on the Kriging method to predict spatial runoff. Gottschalk's method redefines a relevant distance between basins, and identifies the river network and supplemental water balance constraints as follows.

As a spatially integrated continuous process, the predicted runoff of a specific unit of an area $A_{0}$ in a basin, $r^{*}\left(A_{0}\right)$, can be expressed as

$r^{*}\left(A_{0}\right)=\sum_{i=1}^{n} \lambda_{i} r\left(A_{i}\right)$,

where $r\left(A_{i}\right)$ is the observed runoff in a gauged basin $i$ with area $A_{i}(i=1, \ldots n ; n$ is the total number of gauged basins), and $\lambda_{i}$ is the weight of basin $i$.
The weights are obtained by solving the following set of equations under the second-order stationary assumption for hydrologic variables (Ripley, 1976),

$$
\left\{\begin{array}{l}
\sum_{j=1}^{n} \lambda_{i} \operatorname{Cov}\left(u_{i}, u_{j}\right)+\mu=\operatorname{Cov}\left(u_{i}, u_{0}\right), \\
i, j=1,2, \ldots, n \\
\sum_{i=1}^{n} \lambda_{i}=1 .
\end{array}\right.
$$

In Eq. (4), $\operatorname{Cov}\left(u_{i}, u_{j}\right)$ is the theoretical covariance function between each pair of gauged stations $(i=1, \ldots, n, j=1$, $2, \ldots, n), \operatorname{Cov}\left(u_{i}, u_{0}\right)$ is the theoretical covariance of runoff between the location of interest $u_{0}$ and each of the gauged stations $u_{i}$, and $\mu$ is the Lagrange multiplier.

The sum of the interpolated runoff for each nonoverlapping sub-basin should be equal to the observed runoff at the river outlet. This constraint can be written as

$R_{T}=\sum_{i=1}^{M} \Delta A_{i} r\left(\Delta A_{i}\right)$

where $R_{T}$ is the streamflow observed at the outlet of the basin, $\Delta A_{i}$ is the non-overlapping area of sub-basin $i$, and $r\left(\Delta A_{i}\right)$ is the runoff depth for sub-basin $i(i=1, \ldots, M)$. The predicted runoff for each $\Delta A_{i}$ is a linear combination of the weights and the runoff observed in the $n$ sub-basins, i.e., $r\left(\Delta A_{i}\right)=\sum_{j=1}^{n} \lambda_{j}^{i} r\left(A_{j}\right)$. Substituting it in Eq. (5), we get

$R_{T}=\sum_{i=1}^{M} \Delta A_{i}\left(\sum_{j=1}^{n} \lambda_{j}^{i} r\left(A_{j}\right)\right)$.

In Eq. (6), $r\left(A_{j}\right)$ is the runoff depth for sub-basin $j(j=1$, $\ldots, n)$ with discharge observations, and $\lambda_{j}^{i}$ is the weight $(i=$ $1, \ldots, M ; j=1, \ldots, n)$. Further considering the basin area in the river network, Sauquet et al. (2000) derived the weight matrices and described a hydro-stochastic method to optimize the weights $\lambda_{j}^{i}(i=1, \ldots, M ; j=1, \ldots, n)$ in Eq. (6).

The theoretical covariogram, $\operatorname{Cov}(\mathrm{AB})$, is derived by averaging the point process covariance function $\operatorname{Cov}_{p}$

$$
\operatorname{Cov}(\mathrm{AB})=\frac{1}{\mathrm{AB}} \iint_{\mathrm{AB}} \operatorname{Cov}_{\mathrm{p}}\left(\left\|u_{1}-u_{2}\right\|\right) d u_{1} d u_{2}
$$

where $\operatorname{Cov}_{\mathrm{p}}\left(|| u_{1}-u_{2} \|\right)$ is the theoretical covariance function value of pairs of points in basins A and $\mathrm{B}$ with distance $d=$ $\left\|u_{1}-u_{2}\right\|$.

The distance $d(\mathrm{AB})$ is calculated based on grid division in each of the sub-basins (Sauquet et al., 2000). The trial-anderror fitting method is used to calibrate $\operatorname{Cov}_{\mathrm{p}}(d)$ in Eq. (7) to best fit $\operatorname{Cov}_{\mathrm{e}}(d)$. Only independent sub-basins are used to calculate the covariance function to avoid spatial correlation of nested sub-basins.

\subsection{Coupling the stochastic interpolation with the Budyko method}

The above stochastic interpolation procedure assumes a stationary stochastic variation of the runoff among sub-basins or 
spatial homogeneity in runoff (Sauquet, 2006), despite variations in river networks. For nonstationary variations in the runoff resulting from spatial heterogeneity in a river network, the spatial runoff can be decomposed into a nonstationary deterministic component and a stochastic component:

$R(x)=R_{\mathrm{d}}(x)+R_{\mathrm{S}}(x)$.

In Eq. (8), $R(x)$ is the runoff at a location $x$, and $R_{\mathrm{d}}(x)$ is the deterministic component of the spatial trend or the external drift (Wackernagel, 1995) that results in nonstationary variability in space. $R_{\mathrm{S}}(x)$ is the stochastic component considered to be stationary.

In this study, $R$ in Eq. (2) is used as an external drift function in estimating the $R_{\mathrm{d}}(x)$ in all sub-basins; i.e., $R_{\mathrm{d}}(x)$ in Eq. (8) is substituted in Eq. (2) by setting $R_{\mathrm{d}}(x)=R$. The residuals between $R_{\mathrm{d}}(x)$ and the observed runoff are calculated for all gauged sub-basins. Furthermore, these residuals are interpolated for all ungauged sub-basins and set as the stochastic component $R_{\mathrm{S}}(x)$ in Eq. (8) using the "residual kriging" method (Sauquet, 2006). In particular, $R_{\mathrm{S}}(x)$ in Eq. (8) is replaced by $r^{*}\left(A_{0}\right)$ in Eq. (3) after setting $r^{*}\left(A_{0}\right)=R_{\mathrm{S}}(x)$ for the stochastic interpolation scheme described in Sect. 2.2. The superposition of these estimates of both components on the right-hand side in Eq. (8) yields the prediction of $R(x)$.

\subsection{Cross-validation}

To validate this prediction procedure, we use the leaveone-out cross-validation method (Kearns and Ron, 1999). In addition to quantifying the performance of our coupled Budyko and hydro-stochastic interpolation method, we compare and contrast its performance with the Budyko and hydro-stochastic interpolation methods alone. Their performances are evaluated by the following metrics (Laaha and Blöschl, 2006):

$$
\begin{aligned}
\text { MAE } & =\frac{1}{n} \sum_{j=1}^{n}\left[R\left(x_{i}\right)-R^{*}\left(x_{i}\right)\right], \\
\mathrm{MSE} & =\frac{1}{n} \sum_{j=1}^{n}\left[R\left(x_{i}\right)-R^{*}\left(x_{i}\right)\right]^{2}, \\
\mathrm{RMSE} & =\sqrt{\frac{1}{n} \sum_{j=1}^{n}\left[R\left(x_{i}\right)-R^{*}\left(x_{i}\right)\right]^{2},}
\end{aligned}
$$

where $R^{*}(x)$ and $R(x)$ are the predicted and observed runoff, respectively, MAE is the mean absolute error, MSE is the mean-square error, and RMSE is the root-mean-square error. The determination coefficient for cross-validation is

$R_{\mathrm{cv}}^{2}=1-\frac{V_{\mathrm{cv}}}{V_{\mathrm{NK}}}$

where $V_{\mathrm{cv}}$ is the MSE, and $V_{\mathrm{NK}}$ is the spatial variance $\left(V_{\mathrm{NK}}=\frac{\sum_{j=1}^{n}\left[R\left(x_{i}\right)-\bar{R}\right]^{2}}{n-1}\right.$, in which $\bar{R}$ is the mean $\left.R(x)\right)$ of the runoff over all of the tested sub-basins. In addition to these evaluation metrics, the prediction result is evaluated by regression analysis of the observation vs. the prediction.

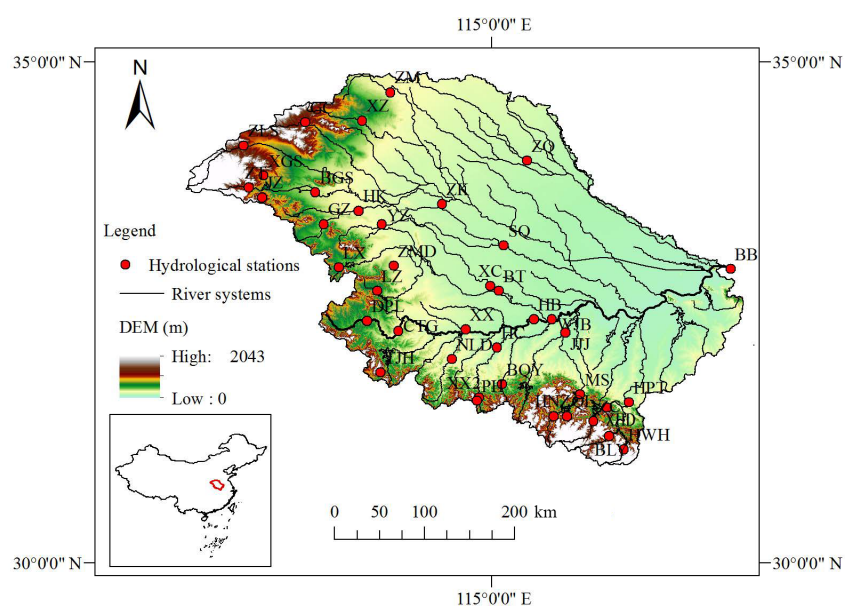

Figure 1. The topography and river network of the study area.

\section{Study catchment and data}

The HRB, the sixth largest river basin in China, is used in evaluation of our coupled model and in its comparison to the other two methods. The HRB has a strong precipitation gradient from the humid climate in the east and the semi-humid climate in the west (Hu, 2008). It is one of the major agricultural areas in China, with the highest human population density in the country. About 18 billion $\mathrm{m}^{3}$ of water was consumed in 1998 to meet the basin's domestic and agriculture needs. Water resources per capita and per unit area are less than one-fifth of the national average. Moreover, more than $50 \%$ of the water resources are exploited, much higher than the recommended $30 \%$ for inland river basins (Yan et al., 2011). Moreover, the concentrated annual precipitation in a few very rainy months makes the region highly vulnerable to severe floods or droughts (Zhang et al., 2015). Thus, having the knowledge of the spatial distribution of the runoff is vital for water resources planning and management in the region.

Our study area is in the upstream of the Bengbu Sluice in the HRB and is $121000 \mathrm{~km}^{2}$ (Fig. 1). The river network in the area is derived from data packages of the National Fundamental Geographic Information System, developed by the National Geomatics Center of China. The HRB is divided into 40 sub-basins, according to available hydrological stations with records from 1961 to 2000 (Fig. 2). The sub-basins vary in their size from the smallest of $17.9 \mathrm{~km}^{2}$ to the largest of $30630 \mathrm{~km}^{2}$. Among the 40 sub-basins, 27 are independent sub-basins and 13 are nested sub-basins.

Annual precipitation data used in this study are from 1961 to 2000 and are obtained from a monthly mean climatological dataset at $0.5^{\circ}$ spatial resolution. The dataset was developed at the China Meteorological Administration, and is accessible at http://data.cma.cn/data/detail/dataCode/ SURF_CLI_CHN_PRE_MON_GRID_0.5.html (last access: 13 May 2018). The dataset was derived from the observations at 2472 stations in China, using the thin plate spline (TPS) in- 


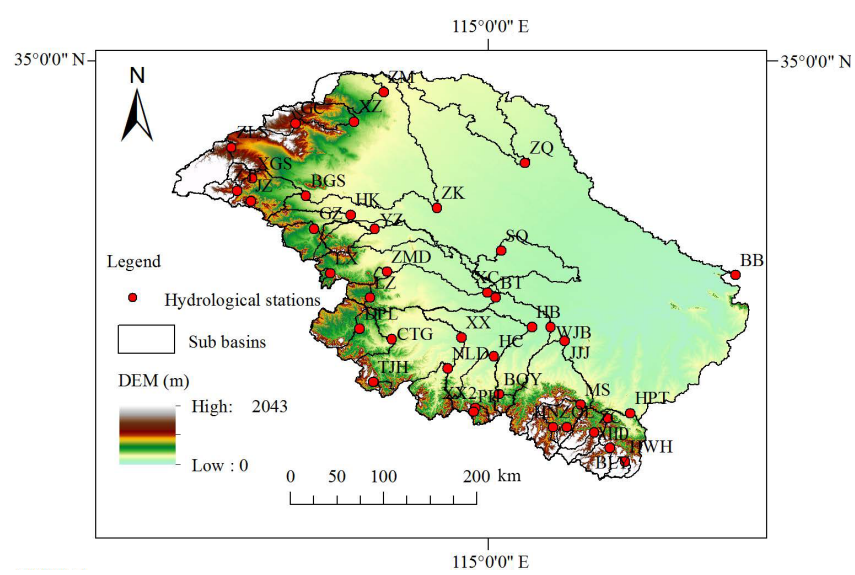

Figure 2. The sub-basins and hydrological stations in the study area.

terpolation method and the ANUSPLIN software. Pan evaporation data at 21 meteorological stations in the HRB are used to interpolate $E_{0}$ by the ordinary Kriging method and the ArcGIS. The interpolated $E_{0}$ are used to derive the annual potential evapotranspiration in the sub-basins. The statistical features of the mean annual precipitation $(P), E_{0}$, and the runoff depth $(R)$ from 1961 to 2000 are summarized in Table 1 . They show that $P$ varied between 638 and $1629 \mathrm{~mm}$, annual temperature was between 11 and $16^{\circ} \mathrm{C}$, and the mean annual $E_{0}$ between 900 and $1200 \mathrm{~mm}$. The sub-basins in the north, e.g., ZM, ZQ, XY, and ZK in Fig. 2, are relatively dry, with the dryness index $\left(E_{0} / P\right)$ above 1.3. The sub-basins in the south, e.g., MS, HBT, and HC, are wetter, with the dryness index below 0.8 . The average mean annual $R$ is about $400 \mathrm{~mm}$, fluctuating from $90 \mathrm{~mm}$ in the north to $1000 \mathrm{~mm}$ in the south. The temporal and spatial variations in the runoff are relatively small in the south and large in the north.

\section{Results}

\subsection{Prediction of runoff by the Budyko method}

Actual evapotranspiration $E$ is estimated using the long-term mean annual water balance $(E=P-R)$ from 1961 to 2000 at the 40 sub-basins, and the results are shown in Table 1. Also shown in Table 1 are the calculated $\omega$ values for the sub-basins. They vary from 1.43 in the sub-basin HWH to 3.16 in JJJ. The average $\omega$ is 2.32 for the 40 sub-basins. The comparison $E / P$ vs. $E_{0} / P$ is shown in Fig. 3 . The best fit (curve) for $E / P$ vs. $E_{0} / P$, or $R$ vs. $E_{0} / P$, is also shown in Fig. 3; it gives an alternative for average $\omega$ of the sub-basins. The fitted value of $\omega$ for the 40 sub-basins determined from this process is 2.213 , very close to that calculated directly from the 40 individual sub-basins.
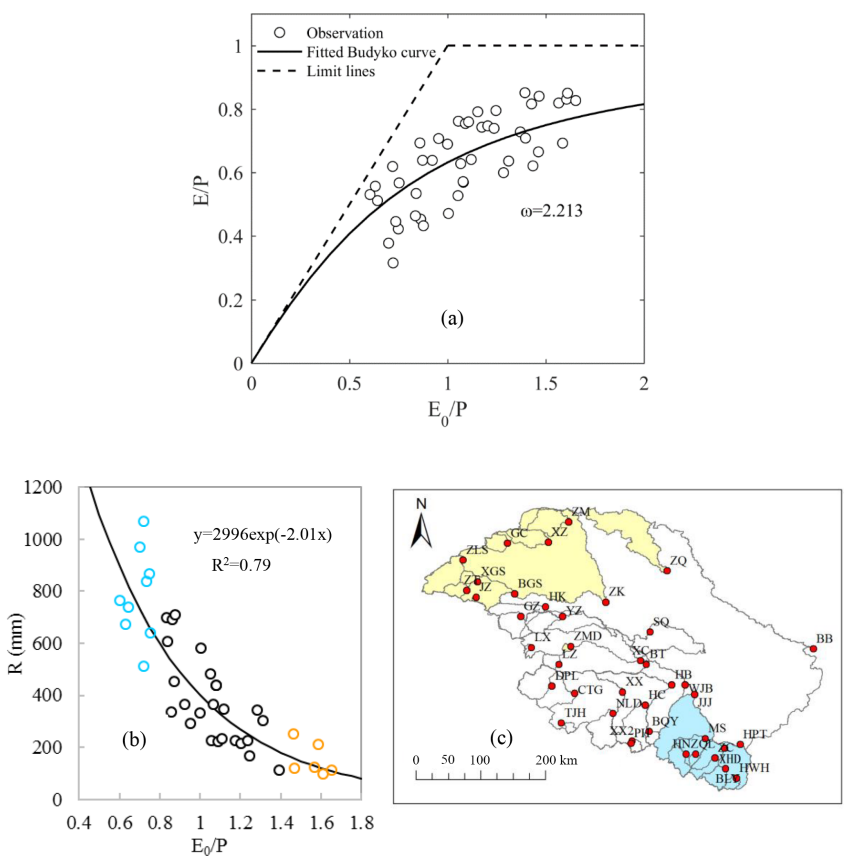

Figure 3. (a) $E / P \sim E_{0} / P$ and (b) $R \sim E_{0} / P$ for the 40 sub-basins (the solid line is the best fit function). (c) The sub-basins in the north and south of the study basin. Note: in (b) and (c), blue color indicates wetter climate in the south and yellow color indicates drier climate in the north.

Using $\omega=2.213$ in the HRB, Fu's equation in Eq. (2) can be written as

$R=P\left(1+\left(\frac{E_{0}}{P}\right)^{2.213}\right)^{\frac{1}{2.213}}-E_{0}$.

Equation (13) and Fig. 3 clearly show the deterministic trend of the runoff in the HRB. According to the water limit criterion, $E=P$, and the energy limit criterion, $E=E_{0}$, in Fig. 3a, the smaller the index $E_{0} / P$ is, the smaller the $E / P$ will be (Fig. 3a) or the larger the runoff will be (Fig. 3b) from the sub-basins in the HRB. In Fig. $3 \mathrm{~b}$ and c, the lower $R$ in the northern sub-basins indicates drier conditions $\left(E_{0} / P>1.4\right)$, whereas the higher $R$ in the southern sub-basins ensures wetter conditions $\left(E_{0} / P<0.8\right)$.

Using $P$ and $E_{0}$ given in Table 1 for the 40 sub-basins, we predict the runoff $R$ by Eq. (13), the Budyko method, and the deviations of their predictions from the observation. The results are summarized in Tables 1 and 2. The MAE of predicted $R$ is $94 \mathrm{~mm}$, and RMSE is $112 \mathrm{~mm}$. The largest absolute error is in the sub-basin HWH $(328 \mathrm{~mm})$, and the smallest in $\mathrm{XX}(24 \mathrm{~mm})$. The largest relative error is $81.6 \%$ of the observed runoff in the sub-basin XZ, and the smallest is $5.0 \%$ of the observed runoff in XHD. They represent absolute errors of 91 and $37 \mathrm{~mm}$ in those two sub-basins, respectively. 
Table 1. Summary of hydro-meteorological data and predicted runoff of the sub-basins in the HRB.

\begin{tabular}{|c|c|c|c|c|c|c|c|c|c|c|c|c|c|c|}
\hline \multirow[t]{2}{*}{ No. } & \multirow[t]{2}{*}{ Station } & \multirow[t]{2}{*}{$\begin{array}{r}\text { Basin area } \\
\left(\mathrm{km}^{2}\right)\end{array}$} & \multirow[t]{2}{*}{$\begin{array}{r}P \\
(\mathrm{~mm})\end{array}$} & \multirow[t]{2}{*}{$\begin{array}{r}R \\
(\mathrm{~mm})\end{array}$} & \multirow[t]{2}{*}{$\begin{array}{r}E_{0} \\
(\mathrm{~mm})\end{array}$} & \multirow[t]{2}{*}{$\begin{array}{r}E_{0} / P \\
(-)\end{array}$} & \multirow[t]{2}{*}{$\begin{array}{r}E \\
(\mathrm{~mm})\end{array}$} & \multicolumn{3}{|c|}{ Budyko method } & \multicolumn{2}{|c|}{$\begin{array}{l}\text { Hydro-stochastic } \\
\text { interpolation }\end{array}$} & \multicolumn{2}{|c|}{ Coupled method } \\
\hline & & & & & & & & $\begin{array}{r}\omega \\
(-)\end{array}$ & $\begin{array}{r}\text { Predicted } R \\
(\mathrm{~mm})\end{array}$ & $\begin{array}{l}\text { Error } \\
(\mathrm{mm})\end{array}$ & $\begin{array}{r}\text { Predicted } R \\
(\mathrm{~mm})\end{array}$ & $\begin{array}{l}\text { Error } \\
(\mathrm{mm})\end{array}$ & $\begin{array}{r}\text { Predicted } R \\
(\mathrm{~mm})\end{array}$ & $\begin{array}{l}\text { Error } \\
(\mathrm{mm})\end{array}$ \\
\hline 1 & CTG & 3090 & 1012 & 366 & 932 & 0.92 & 646 & 2.41 & 399 & 32.85 & 357 & 8.29 & 442 & 75.89 \\
\hline 2 & XHD & 1431 & 1517 & 740 & 974 & 0.64 & 776 & 2.41 & 777 & 36.94 & 819 & 78.85 & 785 & 44.21 \\
\hline 3 & SQ & 3094 & 822 & 168 & 1024 & 1.25 & 653 & 2.83 & 248 & 79.29 & 154 & 14.34 & 189 & 20.40 \\
\hline 4 & MS & 1970 & 1517 & 672 & 957 & 0.63 & 845 & 3.06 & 786 & 114.28 & 705 & 33.18 & 833 & 161.55 \\
\hline 5 & BGS & 2730 & 877 & 225 & 1029 & 1.17 & 651 & 2.57 & 279 & 53.93 & 331 & 105.51 & 321 & 95.80 \\
\hline 6 & $\mathrm{XC}$ & 4110 & 945 & 225 & 997 & 1.06 & 720 & 3.02 & 332 & 106.82 & 197 & 27.83 & 261 & 35.87 \\
\hline 7 & BT & 11280 & 910 & 223 & 993 & 1.09 & 687 & 2.85 & 310 & 86.94 & 205 & 18.10 & 220 & 3.73 \\
\hline 8 & $\mathrm{ZK}$ & 25800 & 678 & 123 & 1061 & 1.56 & 555 & 2.54 & 163 & 39.96 & 101 & 21.54 & 101 & 21.60 \\
\hline 9 & JJJ & 5930 & 1347 & 513 & 969 & 0.72 & 834 & 3.16 & 640 & 127.27 & 369 & 143.29 & 555 & 42.76 \\
\hline 10 & HB & 16005 & 1092 & 335 & 937 & 0.86 & 757 & 3.15 & 455 & 120.48 & 197 & 137.61 & 383 & 48.20 \\
\hline 11 & ZQ & 3410 & 739 & 118 & 1083 & 1.47 & 621 & 2.83 & 190 & 71.71 & 101 & 17.02 & 125 & 7.56 \\
\hline 12 & HPT & 4370 & 1629 & 764 & 984 & 0.60 & 865 & 2.92 & 868 & 103.53 & 729 & 34.69 & 896 & 131.58 \\
\hline 13 & XX & 10190 & 987 & 367 & 1053 & 1.07 & 620 & 2.10 & 343 & 23.77 & 297 & 70.54 & 325 & 41.95 \\
\hline 14 & $\mathrm{BB}$ & 121330 & 850 & 215 & 1024 & 1.20 & 635 & 2.54 & 264 & 49.48 & 71 & 143.43 & 175 & 39.74 \\
\hline 15 & WJB & 30630 & 1003 & 294 & 957 & 0.95 & 709 & 2.85 & 384 & 90.29 & 225 & 68.43 & 280 & 14.17 \\
\hline 16 & $\mathrm{LZ}$ & 390 & 963 & 345 & 1078 & 1.12 & 618 & 2.09 & 320 & 24.96 & 335 & 10.87 & 337 & 8.57 \\
\hline 17 & NLD & 1500 & 1019 & 439 & 1101 & 1.08 & 581 & 1.86 & 351 & 88.30 & 350 & 88.75 & 388 & 50.60 \\
\hline 18 & ZMD & 109 & 690 & 212 & 1093 & 1.58 & 478 & 1.94 & 163 & 48.65 & 265 & 52.90 & 157 & 54.73 \\
\hline 19 & BLY & 737 & 1504 & 868 & 1126 & 0.75 & 635 & 1.69 & 695 & 173.27 & 783 & 85.32 & 861 & 7.54 \\
\hline 20 & HWH & 292 & 1560 & 1068 & 1127 & 0.72 & 492 & 1.43 & 740 & 328.03 & 768 & 299.97 & 852 & 216.14 \\
\hline 21 & $\mathrm{ZC}$ & 493 & 1512 & 838 & 1112 & 0.74 & 674 & 1.79 & 708 & 130.23 & 700 & 137.94 & 790 & 48.34 \\
\hline 22 & BQY & 284 & 1268 & 693 & 1094 & 0.86 & 575 & 1.68 & 527 & 166.21 & 543 & 150.04 & 568 & 125.47 \\
\hline 23 & QL & 178 & 1559 & 970 & 1090 & 0.70 & 589 & 1.60 & 756 & 214.17 & 749 & 221.28 & 749 & 220.34 \\
\hline 24 & HNZ & 805 & 1480 & 640 & 1114 & 0.75 & 840 & 2.41 & 681 & 41.37 & 576 & 63.94 & 816 & 175.57 \\
\hline 25 & TJH & 152 & 1305 & 699 & 1090 & 0.84 & 605 & 1.74 & 556 & 143.66 & 309 & 390.52 & 556 & 143.05 \\
\hline 26 & LX & 77.8 & 1025 & 484 & 1079 & 1.05 & 540 & 1.75 & 361 & 123.77 & 302 & 182.46 & 368 & 116.82 \\
\hline 27 & ZLS & 1880 & 755 & 253 & 1104 & 1.46 & 502 & 1.91 & 194 & 58.45 & 197 & 55.37 & 223 & 29.21 \\
\hline 28 & $\mathrm{ZT}$ & 501 & 1021 & 437 & 1101 & 1.08 & 583 & 1.87 & 351 & 85.87 & 212 & 225.14 & 452 & 14.74 \\
\hline 29 & XGS & 375 & 830 & 302 & 1088 & 1.31 & 528 & 1.91 & 238 & 63.74 & 99 & 202.58 & 317 & 15.33 \\
\hline 30 & $\mathrm{JZ}$ & 46 & 1103 & 583 & 1107 & 1.00 & 520 & 1.63 & 404 & 178.81 & 182 & 401.32 & 463 & 120.48 \\
\hline 31 & $\mathrm{GC}$ & 620 & 638 & 111 & 1055 & 1.65 & 528 & 2.51 & 145 & 34.18 & 53 & 57.92 & 125 & 14.85 \\
\hline 32 & $\mathrm{ZM}$ & 2106 & 645 & 97 & 1039 & 1.61 & 548 & 2.72 & 150 & 53.48 & 72 & 24.71 & 100 & 3.62 \\
\hline 33 & $\mathrm{YZ}$ & 814 & 979 & 235 & 1083 & 1.11 & 743 & 2.85 & 329 & 94.07 & 271 & 35.66 & 321 & 85.76 \\
\hline 34 & $\mathrm{XZ}$ & 1120 & 746 & 111 & 1040 & 1.39 & 636 & 3.06 & 202 & 90.66 & 84 & 27.12 & 163 & 52.32 \\
\hline 35 & GZ & 1030 & 855 & 342 & 1098 & 1.28 & 513 & 1.81 & 250 & 92.10 & 230 & 111.80 & 260 & 81.82 \\
\hline 36 & DPL & 1770 & 1067 & 331 & 1066 & 1.00 & 736 & 2.57 & 393 & 61.62 & 330 & 1.02 & 437 & 105.29 \\
\hline 37 & $\mathrm{XX} 2$ & 256 & 1301 & 606 & 1092 & 0.84 & 695 & 2.00 & 552 & 53.68 & 708 & 101.78 & 732 & 126.63 \\
\hline 38 & $\mathrm{PH}$ & 17.9 & 1248 & 708 & 1094 & 0.88 & 540 & 1.61 & 512 & 196.04 & 605 & 102.78 & 564 & 144.41 \\
\hline 39 & $\mathrm{HC}$ & 2050 & 1255 & 454 & 1095 & 0.87 & 802 & 2.54 & 517 & 63.36 & 328 & 125.79 & 537 & 83.61 \\
\hline 40 & HK & 2141 & 871 & 227 & 1077 & 1.24 & 644 & 2.44 & 264 & 37.28 & 273 & 46.15 & 243 & 16.02 \\
\hline
\end{tabular}

\subsection{Runoff by the hydro-stochastic interpolation method}

For comparison, the observed runoff is used in the hydrostochastic interpolation following the procedure detailed in Sect. 2.2. In order to obtain the distance $d$ between pairs of the sub-basins, the study area is divided into 40 rows $\times 50$ columns. The geostatistical distance between any two subbasins, A and B, is calculated by averaging the distances between all pairs of grid points in $\mathrm{A}$ and $\mathrm{B}$ (all the possible pairs of the sub-basins are $40 \times 41 / 2$ for the 40 sub-basins in this study). According to the estimated distance for the pairs of sub-basins and the observed runoff at the 40 subbasins (Table 1), the empirical covariance $\operatorname{Cov}_{\mathrm{e}}(d)$ is estimated for each pair of the sub-basins. From the plots of the mean $\operatorname{Cov}_{\mathrm{e}}(d)$ of all the independent sub-basin pairs vs. the corresponding distance $d$ with an interval of $20 \mathrm{~km}$, we fit the function of the empirical covariogram shown in Fig. 4. The fitting theoretical covariance function $\operatorname{Cov}_{\mathrm{p}}(d)$ to the empirical covariogram is

$\operatorname{Cov}_{\mathrm{p}}(d)=6 \times 10^{5} \exp (-d / 28.62)$.

This function is used to calculate the average theoretical covariance $\operatorname{Cov}(\mathrm{AB})$ in Eq. (7). Finally, the weight matrices are determined using our programs in MatLab.

The interpolated runoff depth $(R)$ over the 40 sub-basins along with the deviations from the observation are shown in Table 1. The MAE and RMSE of $R$ are 103 and $140 \mathrm{~mm}$, respectively. The largest absolute and relative error is in the sub-basin JZ (401 mm and $68.8 \%$ ), and the smallest is in DPL (1 $\mathrm{mm}$ and $0.3 \%$ ) (Table 2). These results indicate that the errors from this interpolation method are in general larger 


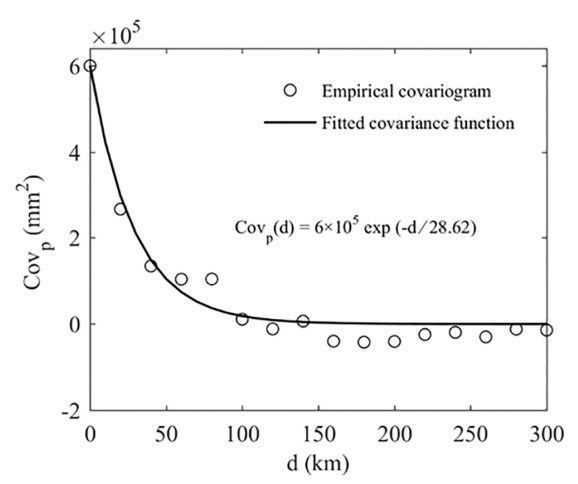

Figure 4. Empirical covariogram $\left(\operatorname{Cov}_{\mathrm{e}}(d)\right)$ from the sub-basin runoff data and theoretical covariogram by the fitted covariance function $\operatorname{Cov}_{\mathrm{p}}(d)$ of the study area.

than those from the Budyko method, suggesting that the observed runoff is more influenced by the deterministic trend in the basin.

\subsection{Hydro-stochastic interpolation with Fu's equation (our coupled method)}

We use Fu's equation, Eq. (2), to evaluate the deterministic trend or the external drift function, $R_{\mathrm{d}}^{*}(x)$, and deviation of the trend from the observation, $R_{\mathrm{S}}^{*}(x)$, assuming a spatially auto-correlated process. The $R_{\mathrm{S}}^{*}(x)$ is then used in the stochastic interpolation.

The empirical residual covariogram of $R_{\mathrm{S}}^{*}(x)$ for each pair of sub-basins vs. sub-basin distance is shown in Fig. 5. From the result in Fig. 5a, we obtain the exponential function for $\operatorname{Cov}_{\mathrm{p}}(d)$ :

$\operatorname{Cov}_{\mathrm{p}}(d)=13030 \exp (-d / 23.9)$.

From Eq. (15), the weight matrices of runoff deviation are determined by Eq. (4) using our program in MatLab. They are then used to predict the runoff deviation. The scatterplot of the predicted residuals vs. the observed residuals shown in Fig. 5b delineates a positive correlation between the predicted and the observed residuals. However, the large scatter indicates limited performance by the residual model alone. Because this interpolation scheme represents the spatial runoff deviation, the sum of the interpolated runoff deviation and the simulated runoff by Fu's equation is the total interpolated runoff in the sub-basins.

The predicted runoff using this procedure is given in Table 1, with the MAE at $71 \mathrm{~mm}$ and RMSE at $93 \mathrm{~mm}$ over the 40 sub-basins. The largest absolute error is in the sub-basin QL $(220 \mathrm{~mm})$, and the smallest in ZM (4 mm) (Table 2). The largest relative error is $47.2 \%$ of the observed runoff in XZ, and the smallest is $1 \%$ of the observed runoff in BLY. They represent the absolute errors of 52 and $8 \mathrm{~mm}$, respectively.
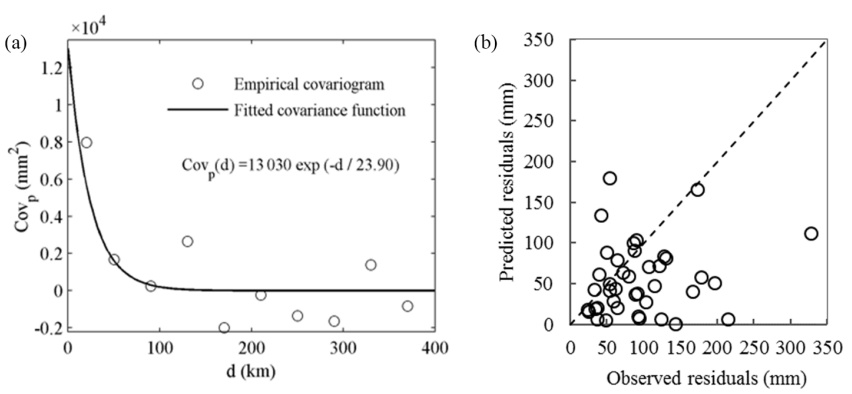

Figure 5. (a) Empirical covariogram $\left(\operatorname{Cov}_{\mathrm{e}}(d)\right)$ from the residual $R_{\mathrm{S}}(x)$ and theoretical covariogram by the fitted covariance function $\operatorname{Cov}_{\mathrm{p}}(d)$ of the study area. (b) The scatterplot of the predicted vs. observed residuals.

\subsection{Comparisons of the predicted runoff by the three methods}

Comparing the results in Table 2, we find that our coupled method of the deterministic and stochastic processes substantially reduces the runoff prediction error in the HRB. The MAE and RMSE of the runoff from our coupled method are much smaller than those from the Budyko or the hydro-stochastic interpolation method. In cross-validation (Table 2), our coupled method has $R_{\mathrm{cv}}^{2}=0.87$, which is larger than 0.81 and 0.71 from the Budyko method and the hydrostochastic interpolation, respectively. The errors in runoff at the sub-basins are significantly reduced as well. The error in the sub-basin HWH is $216 \mathrm{~mm}$ from the coupled method, compared to $328 \mathrm{~mm}$ from the Budyko method and $300 \mathrm{~mm}$ from the hydro-stochastic interpolation. The error in $\mathrm{JZ}$ is $120 \mathrm{~mm}$ from the coupled method, smaller than $179 \mathrm{~mm}$ from the Budyko method and $401 \mathrm{~mm}$ from the hydro-stochastic interpolation.

Our correlation analysis between the predicted and observed $R$ is shown in Fig. 6. The predicted runoff from our coupled method shows higher correlation with the observed one $\left(R^{2}=0.87\right)$, in comparison to the Budyko method $\left(R^{2}=0.82\right)$ and the hydro-stochastic interpolation $\left(R^{2}=0.79\right)$. Our analysis indicates that the latter two methods overestimate low runoff and underestimate high runoff, as indicated by large departures from the $1: 1$ line in Fig. 6 . Similarly, large deviations of the runoff predicted by the hydro-stochastic interpolation have also been reported by Sauquet et al. (2000), Laaha and Blöschl (2006), and Yan et al. (2011).

The spatial distributions of the runoff in the HRB calculated from the three methods are shown in Fig. 7. They again show significant differences. Compared to the result from our coupled method (Fig. 7c), the Budyko method overestimates the runoff in most of the northern sub-basins (Fig. 7a), where the climate is relatively dry and runoff is small (ranging from 140 to $280 \mathrm{~mm}$ ). The hydro-stochastic interpolation method underestimates the runoff in some southern sub- 
Table 2. Interpolation cross-validation errors between the predicted and observed runoff in the 40 sub-basins in the HRB from the three methods.

\begin{tabular}{lrrr}
\hline Evaluation indicators & Budyko method & Hydro-stochastic interpolation & Coupling method \\
\hline MAE (mm) & 94 & 103 & 71 \\
MSE (mm $\left.{ }^{2}\right)$ & 12561 & 19828 & 8557 \\
RMSE (mm) & 112 & 140 & 93 \\
Max absolute error (mm) & 328 & 401 & 220 \\
Min absolute error (mm) & 24 & 1 & 4 \\
Max relative error (\%) & 82 & 69 & 47 \\
Min relative error (\%) & 5 & 0.3 & 1 \\
$R_{\mathrm{cv}}^{2}(-)$ & 0.81 & 0.71 & 0.87 \\
\hline
\end{tabular}
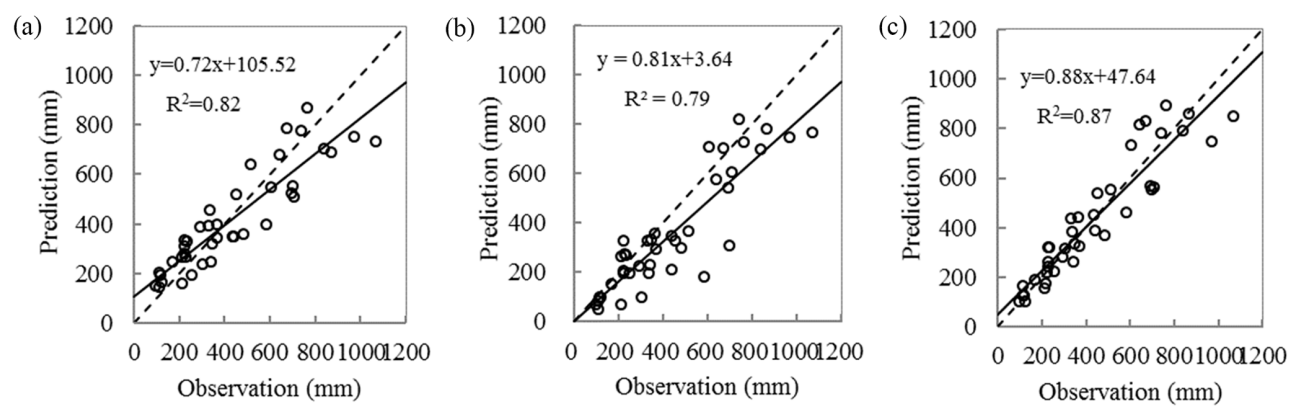

Figure 6. Cross-validation of the predicted runoff vs. the observation by (a) the Budyko method, (b) hydro-stochastic interpolation, and (c) our coupled method. The dashed line is $1: 1$.

basins (Fig. 7b), where the wet climate has fostered extremely high runoff $(800-1100 \mathrm{~mm})$, such as in the subbasins HWH, BLY, and ZC (Table 1). The results from our coupled method are closest to the observed distribution of the runoff among the three methods (Fig. 7d). Compared to the errors in the predicted runoff by the Budyko method and the hydro-stochastic interpolation (Fig. 7 and Table 1), our coupled method reduces the error in $70 \%$ of all the sub-basins (28 of the 40 sub-basins).

\section{Discussions and conclusions}

In this study, we use the Budyko deterministic method to describe the mean annual runoff, which is an integrated spatially continuous process and determined by both the hydro-climatic elements and the hierarchical river network. A deviation from the Budyko estimated runoff is used by the stochastic interpolation that assumes spatially autocorrelated error. The deterministic aspects of the runoff described in the Budyko method are reflected in the trends at locations (sub-basins), and deviations from the trends caused by the stochastic processes are described by the weights as a function of the autocorrelation and distance. Information from both the Budyko method and the stochastic interpolation are integrated into our coupled method to predict the runoff.
Different from the universal Kriging method, in which the trend is represented as a linear function of coordinate variables and determined solely through spatial data calibration (i.e., semi-variogram analysis), the Budyko method couples water and energy balance and could directly predict streamflow in ungauged basins. This physically based method relies on using the spatial trend of runoff and, in our study, it yields the deterministic coefficient of cross-validation, $R_{\mathrm{cv}}^{2}$, to be 0.81 , better than that from the hydro-stochastic interpolation method.

Incorporating secondary information into the geostatistical methods improves the estimate of a predictive variable, e.g., the estimate of groundwater level by incorporating topography into the collocated co-Kriging (Boezio et al., 2006), or the estimate of mean annual stream temperature by incorporating a nonlinear relationship between the mean annual stream temperature and altitude of the stream gauge into the top Kriging (Laaha et al., 2013). By incorporating such secondary information and the relationship between the mean runoff and the climate conditions (the aridity index) into the Budyko method through coupling with the hydro-stochastic interpolation, we develop our new coupled Budyko-hydro-stochastic interpolation method. It can substantially improve the prediction of streamflow in ungauged basins. This improvement is shown by the higher $R_{\mathrm{cv}}^{2}$ of 0.87 in the HRB, compared to 0.81 and 0.71 by the Budyko and hydro-stochastic interpolation methods, respectively. More- 

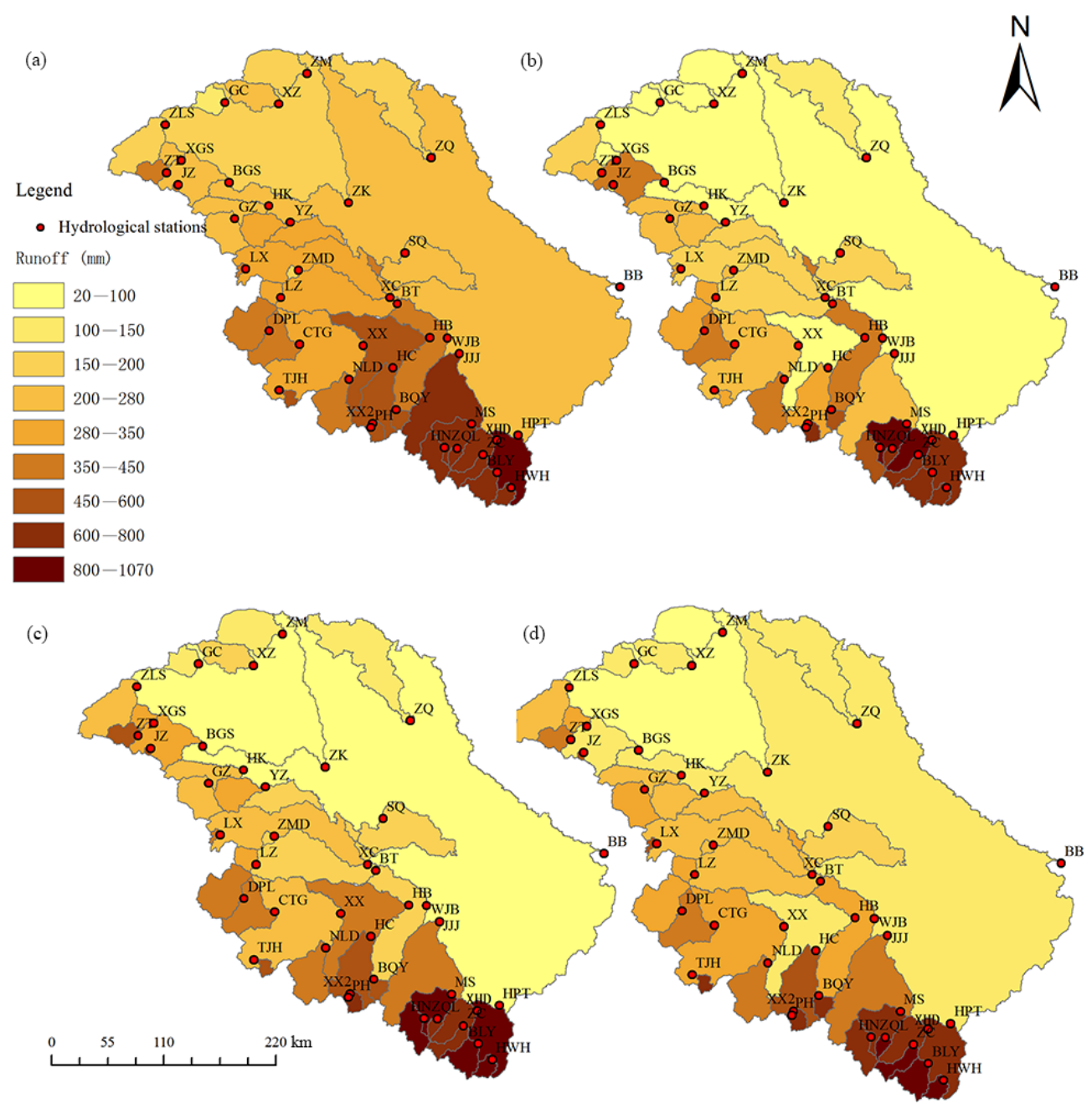

Figure 7. Spatial distribution of the mean annual runoff estimated from (a) the Budyko method, (b) hydro-stochastic interpolation, (c) our coupled method, and (d) the observation.

over, for high and low runoffs in the sub-basins of the HRB, our coupled method gives more accurate predictions.

While substantial progress has been made by our coupled method, its results show room for improvement to further increase the accuracy of runoff prediction. For example, runoff prediction errors remain large from our coupled method in some sub-basins in the HRB. In the sub-basins MS, QL, $\mathrm{HWH}$, and HNZ, the absolute error of predicted runoff is larger than $150 \mathrm{~mm}$ and the relative error of predicted runoff is larger than $20 \%$ of the observed runoff. In the sub-basins BGS and XZ, the relative error of the predicted runoff is larger than $40 \%$ of the observed runoff. These errors are largely attributable to large prediction errors intrinsic to the Budyko method (e.g., MS, QL, HWH, and XZ in Table 1). Possible causes of the errors could be from additional external factors influencing the runoff, such as land cover, soil properties, hydro-climatic variations, and the groundwater. Including some or all of these effects to improve the Budyko method or incorporating these effects as secondary infor- mation (e.g., multi-collocated co-Kriging) into our coupled model would help aid our understanding of the deterministic processes and increase the runoff prediction accuracy.

Data availability. The precipitation dataset can be accessed at http://data.cma.cn/data/detail/dataCode/SURF_CLI_CHN_PRE_ MON_GRID_0.5.html (last access: 13 May 2018). The original runoff and evapotranspiration data can not be publicly accessed.

Competing interests. The authors declare that they have no conflict of interest.

Acknowledgements. We thank the editor Erwin Zehe and the reviewers Mirko Mälicke and Jon Olav Skøien for their valuable comments and suggestions that helped improve this paper substantially. The research was supported by the National Natural 
Science Foundation of China (nos. 51190091 and 41571130071). Qi Hu's contribution was supported by USDA Cooperative Project NEB-38-088.

Edited by: Erwin Zehe

Reviewed by: Mirko Mälicke and Jon Olav Skøien

\section{References}

Arnell, N. W.: Factors controlling the effects of climate change on river flow regimes in a humid temperate environment, J. Hydrol., 132, 321-342, 1992.

Arnell, N. W.: Grid mapping of river discharge, J. Hydrol., 167, 39_ 56, 1995.

Barancourt, C., Creutin, J. D., and Rivoirard, J.: A method for delineating and estimating rainfall fields, Water Resour. Res., 28, 1133-1144, 1992.

Berghuijs, W. R., Woods, R. A., and Hrachowitz, M.: A precipitation shift from snow towards rain leads to a decrease in streamflow, Nature Clim. Change, 4, 583-586, 2014.

Blöschl, G.: Rainfall-runoff modelling of ungauged catchments, Article 133, in: Encyclopedia of Hydrological Sciences, edited by: Anderson, M. G., Wiley, Chicester, 2061-2080, 2005.

Boezio, M. N. M., Costa, J. F. C. L., and Koppe, J. C.: Kriging with an external drift versus collocated cokriging for water table mapping, Applied Earth Science, 115, 103-112, 2006.

Budyko, M. I.: Methods for determining the components of the heat balance, Climate and Life, Academic Press, New York, 1974.

Choudhury, B.: Evaluation of an empirical equation for annual evaporation using field observations and results from a biophysical model, J. Hydrol., 216, 99-110, 1999.

Creutin, J. D. and Obled, C.: Objective analysis and mapping techniques for rainfall fields an objective comparison, Water Resour. Res., 18, 413-431, 1982.

Dingman, S. L., Seely-Reynolds, D. M., and Reynolds, R. C.: Application of kriging to estimating mean annual precipitation in a region of orographic influence, Water Resour. Bull., 24, 329339,1988

Donohue, R. J., Roderick, M. L., and McVicar, T. R.: On the importance of including vegetation dynamics in Budyko's hydrological model, Hydrol. Earth Syst. Sci., 11, 983-995, https://doi.org/10.5194/hess-11-983-2007, 2007.

Donohue, R. J., Roderick, M. L., and McVicar, T. R.: Roots, storms and soil pores: Incorporating key ecohydrological processes into Budyko's hydrological model, 436-437, 35-50, 2012.

Dooge, J. C. I.: Looking for hydrologic laws, J. Hydrol., 96, 3-4, 1986.

$\mathrm{Fu}, \mathrm{B} .:$ On the calculation of the evaporation from land surface, Sci. Atmos. Sin., 1, 23-31, 1981 (in Chinese).

Gao, M., Chen, X., Liu, J., and Zhang, Z.: Regionalization of annual runoff characteristics and its indication of co-dependence among hydro-climate-landscape factors in Jinghe River Basin, China, Stoch. Env. Res. Risk A, 1-18, https://doi.org/10.1007/s00477017-1494-9, 2017.

Gentine, P., D’Odorico, P., Lintner, B. R., Sivandran, G., and Salvucci, G.: Interdependence of climate, soil, and vegetation as constrained by the Budyko curve, Geophys. Res. Lett., 39, L19404, https://doi.org/10.1029/2012GL053492, 2012.
Gerrits, A. M. J., Savenije, H. H. G., Veling, E. J. M., and Pfister, L.: Analytical derivation of the Budyko curve based on rainfall characteristics and a simple evaporation model, Water Resour. Res., 45, W04403, https://doi.org/10.1029/2008WR007308, 2009.

Gottschalk, L.: Correlation and covariance of runoff, Stoch. Hydrol. Hydraul., 7, 85-101, 1993a.

Gottschalk, L.: Interpolation of runoff applying objective methods, Stoch. Hydrol. Hydraul., 7, 269-281, 1993b.

Gottschalk, L., Krasovskaia, I., Leblois, E., and Sauquet, E.: Mapping mean and variance of runoff in a river basin, Hydrol Earth Syst. Sci., 10, 469-484, https://doi.org/10.5194/hess-10469-2006, 2006.

Goovaerts, P.: Geostatistics for natural resources evaluation, Oxford University Press on Demand, New York, 1997.

Greenwood, A. J. B., Benyon, R. G., and Lane, P. N. J.: A method for assessing the hydrological impact of afforestation using regional mean annual data and empirical rainfall-runoff curves, J. Hydrol., 411, 49-65, 2011.

Greve, P., Orlowsky, B., Mueller, B., Sheffield, J., Reichstein, M., and Seneviratne, S. I.: Global assessment of trends in wetting and drying over land, Nat. Geosci., 7, 716-721, 2014.

Han, S., Hu, H., Yang, D., and Liu, Q.: Irrigation impact on annual water balance of the oases in Tarim Basin, Northwest China, Hydrol. Process, 25, 167-174, 2011.

Hisdal, H. and Tveito, O. E.: Generation of runoff series at ungauged locations using empirical orthogonal functions in combination with kriging, Stoch. Hydrol. Hydraul., 6, 255-269, 1993.

Holman, I. P., Tascone, D., and Hess, T. M.: A comparison of stochastic and deterministic downscaling methods for modelling potential groundwater recharge under climate change in East Anglia, UK: implications for groundwater resource management, Hydrogeol. J., 17, 1629-1641, 2009.

Hu, W. W., Wang, G. X., Deng, W., and Li, S. N.: The influence of dams on eco hydrological conditions in the Huaihe River basin, China, Ecol. Eng., 33, 233-241, 2008.

Imbach, P., Molina, L., Locatelli, B., Roupsard, O., Ciais, P., Corrales, L., and Mahé, G.: Climatology-based regional modelling of potential vegetation and average annual long-term runoff for Mesoamerica, Hydrol. Earth Syst. Sci., 14, 1801-1817, https://doi.org/10.5194/hess-14-1801-2010, 2010.

Istanbulluoglu, E., Wang, T., Wright, O. M., and Lenters, J. D.: Interpretation of hydrologic trends from a water balance perspective: The role of groundwater storage in the Budyko hypothesis, Water Resour. Res., 48, 273-279, 2012.

Jiang, C., Xiong, L., Wang, D., Liu, P., Guo, S., and Xu, C. Y.: Separating the impacts of climate change and human activities on runoff using the Budyko-type equations with time-varying parameters, J. Hydrol., 522, 326-338, 2015.

Jones, O. D.: A stochastic runoff model incorporating spatial variability, 18th world IMACS CONGRESS AND MODSIM09 International congress on modelling and simulation: interfacing modelling and simulation with mathematical and computational sciences, 157, 1865-1871, 2009.

Kearns, M. and Ron, D.: Algorithmic stability and sanity-check bounds for leave-one-out cross-validation, Neural Comput., 11, 1427-1453, 1999.

Koster, R. D. and Suarez, M. J.: A simple framework for examining the inter annual variability of land surface moisture fluxes, J. Climate, 12, 1911-1917, 1999. 
Laaha, G. and Blöschl, G.: Seasonality indices for regionalizing low flows, Hydrol. Process., 20, 3851-3878, 2006.

Laaha, G., Skøien, J. O., Nobilis, F., and Blöschl, G.: Spatial prediction of stream temperatures using Top-kriging with an external drift, Environ. Model. Assess., 18, 671-683, 2013.

Legates, D. R. and McCabe, G. J.: Evaluating the use of "goodnessof-fit" measures in hydrologic and hydroclimatic model validation, Water Resour. Res., 35, 233-241, 1999.

Lenton, R. L. and Rodriguez-Iturbe, I.: Rainfall network system analysis: the optimal esimation of total areal storm depth, Water Resour. Res., 13, 825-836, 1977.

Li, D., Pan, M., Cong, Z., Zhang, L., and Wood, E.: Vegetation control on water and energy balance within the Budyko framework, Water Resour. Res., 49, 969-976, 2013.

Li, J. and Heap, A. D.: A review of spatial interpolation methods for environmental scientists, Record - Geoscience Australia, 1-137, 2008.

Milly, P. C. D.: Climate, soil water storage, and the average annual water balance, Water Resour. Res., 30, 2143-2156, 1994.

Parajka, J. and Szolgay, J.: Grid-based mapping of long-term mean annual potential and actual evapotranspiration in Slovakia, IAHS Publications-Series of Proceedings and Reports-Intern Assoc. Hydrological Sciences, 248, 123-130, 1998.

Porporato, A., Daly, E., and Rodriguez-Iturbe, I.: Soil water balance and ecosystem response to climate change, Am. Nat., 164, 625632, 2004.

Potter, N. J. and Zhang, L.: Inter annual variability of catchment water balance in Australia, J. Hydrol., 369, 120-129, 2009.

Qiao, C. F.: Mapping runoff isocline of Hai, Luan River basin, Hydrology, s1, 63-66, 1982.

Ripley, B. D.: The second-order analysis of stationary point processes, J. Appl. Probab., 13, 255-266, 1976.

Sauquet, E.: Mapping mean annual river discharges: Geostatistical developments for incorporating river network dependencies, J. Hydrol., 331, 300-314, 2006.

Sauquet, E., Gottschalk, L., and Leblois, E.: Mapping average annual runoff: a hierarchical approach applying a stochastic interpolation scheme, Hydrolog. Sci. J., 45, 799-815, 2000.

Shao, Q., Traylen, A., and Zhang, L.: Nonparametric method for estimating the effects of climatic and catchment characteristics on mean annual evapotranspiration, Water Resour. Res., 48, W03517, https://doi.org/10.1029/2010WR009610, 2012.

Sivapalan, M.: Pattern, processes and function: elements of a unified theory of hydrology at the catchment scale, in: Encyclopedia of hydrological sciences, edited by: Anderson, M., John Wiley, London, 193-219, 2005.

Sivapalan, M., Takeuchi, K., Franks, S. W., Gupta, V. K., Karambiri, H., Lakshmi, V., Liang, X., McDonnell, J. J., Mendiondo, E. M., O'Connell, P. E., Oki, T., Pomeroy, J. W., Schertzer, D., Uhlenbrook, S., and Zehe, E.: Iahs decade on predictions in ungauged basins (pub), 2003-2012: shaping an exciting future for the hydrological sciences, Hydrolog. Sci. J., 48, 857-880, 2003.
Skøien, J. O., Merz, R., and Blöschl, G.: Top-kriging - geostatistics on stream networks, Hydrol. Earth Syst. Sci., 10, 277-287, https://doi.org/10.5194/hess-10-277-2006, 2006.

Tabios, G. Q. and Salas, J. D.: A comparative analysis of techniques for spatial interpolation of precipitation, Water Resour. Bull., 21, 365-380, 1985.

Villeneuve, J. P., Morin, G., Bobée, B., Leblanc, D., and Delhomme, J. P.: Kriging in the design of streamflow sampling networks, Water Resour. Res., 15, 1833-184, 1979.

Wackernagel, H.: Multivariate geostatistics, Springer, Berlin, 1995.

Wagener, T., Sivapalan, M., Troch, P., and Woods, R.: Catchment classification and hydrologic similarity, Geography Compass, 1, 901-931, 2007.

Wang, D. and Tang, Y.: A one-parameter Budyko model for water balance captures emergent behavior in darwinian hydrologic models, Geophys. Res. Lett., 41, 4569-4577, 2014.

Williams, C. A., Reichstein, M., Buchmann, N., Baldocchi, D., Beer, C., Schwalm, C., Wohlfahrt, G., Hasler, N., Bernhofer, C., Foken, T., Papale, D., Schymanski, S., and Schaefer, K.: Climate and vegetation controls on the surface water balance: Synthesis of evapotranspiration measured across a global network of flux towers, Water Resour. Res., 48, W06523, https://doi.org/10.1029/2011WR011586, 2012.

Xu, X., Liu, W., Scanlon, B. R., Zhang, L., and Pan, M.: Local and global factors controlling water-energy balances within the Budyko framework, Geophys. Res. Lett., 40, 6123-6129, 2013.

Yan, Z., Xia, J., and Gottschalk, L.: Mapping runoff based on hydrostochastic approach for the Huaihe River Basin, China, J. Geogr. Sci., 21, 441-457, 2011.

Yang, D., Sun, F., Liu, Z., Cong, Z., Ni, G., and Lei, Z.: Analyzing spatial and temporal variability of annual water-energy balance in non-humid regions of China using the Budyko hypothesis, Water Resour. Res, 43, 436-451, 2007.

Yang, H., Yang, D., Lei, Z., and Sun, F.: New analytical derivation of the mean annual water-energy balance equation, Water Resour. Res., 44, 893-897, 2008.

Zhang, L., Dawes, W. R. G., and Walker, R.: Response of mean annual evapotranspiration to vegetation changes at catchment scale, Water Resour. Res., 37, 701-708, 2001.

Zhang, L., Hickel, K., Dawes, W. R., Chiew, F. H., Western, A. W., and Briggs, P. R.: A rational function approach for estimating mean annual evapotranspiration, Water Resour. Res., 40, W02502, https://doi.org/10.1029/2003WR002710, 2004.

Zhang, R., Chen, X., Zhang, Z., and Shi, P.: Evolution of hydrological drought under the regulation of two reservoirs in the headwater basin of the Huaihe River, China, Stoch. Env. Rese. Risk A., 29, 487-499, 2015. 